\title{
Design and Activation of a LOX/GH Chemical Steam Generator
}

\author{
G.P. Saunders ${ }^{1}$ \\ Jacobs Technology Group, Stennis Space Center, MS, 39529 \\ and \\ C.A. Mulkey ${ }^{2}$ and S.A. Taylor ${ }^{3}$ \\ National Aeronautics and Space Administration, Stennis Space Center, MS, 39529
}

\begin{abstract}
The purpose of this paper is to give a detailed description of the design and activation of the LOX/GH fueled chemical steam generator installed in Cell 2 of the E3 test facility at Stennis Space Center, MS (SSC). The steam generator uses a liquid oxygen oxidizer with gaseous hydrogen fuel. The combustion products are then quenched with water to create steam at pressures from 150 to 450 psig at temperatures from 350 to $750 \mathrm{deg} F$ (from saturation to piping temperature limits).
\end{abstract}

\section{Nomenclature}

SSC $=$ Stennis Space Center, MS

$S D T=$ Subscale Diffuser Test Project

$E 3 C 1=$ Refers to test cell 1 at test facility E3 at the E-complex at SSC

$E 3 C 2=$ Refers to test cell 2 at test facility E3 at the E-complex at SSC

$\mathrm{LH}=\mathrm{L}=\mathrm{Liquid}$ Hydrogen

$L O X=$ Liquid Oxygen

GH $\quad=$ Gaseous Hydrogen

\section{Introduction}

$\mathrm{T}$

HIS document provides a description of the design and activation of the LOX/GH fueled chemical steam generator installed in Cell 2 of the E3 test facility (E3C2) at Stennis Space Center, MS (SSC). The A3 Subscale Diffuser (SDT) project, located at the adjacent test cell (E3C1), requires a superheated steam supply of 20pps at approximately $400 \mathrm{psig}$. Details regarding SDT facility requirements and test hardware design can be found in References 1-4.

During the initial planning phases of the SDT project, it was decided that the steam supply system would be rented, meaning a commercial style portable boiler system be rented and brought on site. It was soon apparent that renting commercial boiler steam was not feasible due to cost, schedule, and boiler hardware risk. The initial capital expenditure was found to be exorbitant partly because SSC does not have the infrastructure to support the fuel demands of such a large boiler. The rental cost alone over the projected life of the project was estimated to exceed the total project budget. Commercial boiler systems also require a lengthy warm up period and are designed for steady-state operation. The duty-cycle required for the SDT project required steam for 60 to 180 seconds at a time, a couple of times a day, leading to concerns about potential high-cycle fatigue damage to boiler tubes. Therefore the decision was made to create steam using existing rocket hardware. The cost of building and operating a chemical steam generator was recognized as a much more cost effective alternative. However, the technical risk of such an endeavor was considered much higher.

The rocket hardware selected for use as the steam generator combustor was part of the so-called DTF (Diagnostic Testbed Facility) rocket used in the late 1980's at SSC for plume diagnostic studies. The DTF rocket is

${ }^{1}$ A3 Subscale Test Project Manager, Building 3226, Stennis Space Center, MS, 39529, Senior Member.

2 Mechanical Engineer, Engineering and Science Directorate, Building 3225, SSC, MS 39529.

${ }^{3}$ Systems Engineer, Engineering and Science Directorate, Building 3225, SSC, MS 39529. 
a pressure fed LOX/GH rocket with multiple co-axial (LOX post) injectors, capable of producing approximately $1000 \mathrm{lbf}$ of thrust. A new combustion chamber liner was designed without a sonic throat and a spray cooler was added to quench the combustion gases to create the steam required for diffuser testing at $\mathrm{E} 3 \mathrm{C} 1$.

\section{Design}

The steam generation system for E3C2 was designed over two month period between May 2007 and July 2007. Fabrication was completed and activation began in earnest by September 2007. Early rough calculation showed that when utilizing a LOX/GH combustor at a reasonable mixture ratio $(\mathrm{O} / \mathrm{F} \sim 6)$ a water-to-propellant mass ratio of about 4 to 1 was required to generate superheated steam at the same design temperature as the LOX/IPA chemical generators selected for use at the A3 test facility. The A3 Subscale Diffuser Test (SDT) project requires approximately $20 \mathrm{pps}$ of steam flow. While investigating potential sources of energy to generate the steam requirements of the SDT, it was discovered that the DTF rocket used in the late 1980's at SSC had been run in the desired flow rate range. Therefore the decision was made to modify hardware remaining from the DTF program for use as a combustor in an integral combustor/spray cooler steam generator.

\section{A. Combustor}

Similar to the existing DTF combustion hardware, the steam generator combustor uses a water cooled copper liner in the combustor with high velocity water flowing countercurrent to the combustion gas direction on outside surface of the liner. Unlike the DTF hardware, application as a steam generator combustor requires subsonic exit gas to keep the exit dynamic pressure sufficiently low such that water can be injected downstream and penetrate the combustor exit gas enough to promote good mixing. Therefore, a new "no throat" liner was designed to fit the existing pressure casing and fuel/oxidizer injector hardware. The inside surface of the resultant liner is simply a straight cylinder. Other modifications to the original hardware design include a new liner baffle to accurately locate the liner in the pressure casing and create a portion of the backside cooling water passage, and a threaded flange at the combustor exit to allow the spray cooler to be attached aft the combustor.

Another significant piece of hardware integral to the successful operation of the steam generator is affectionately referred to as the splatter ring. The splatter ring is device designed to prevent the hot combustion gases from expanding and impinging against the spray cooler wall as the flow exits the combustor and enters the cooler. The splatter ring has a constant radius contoured ramp on its outer surface. It extends into the spray cooler such that the first row of water injection holes impinge on the outer surface contour. The water flow then spreads into a thin conical sheet and exits the ramp at a slight angle relative to the combustor/spray cooler axis. The "exit" of the conical water sheet is the same plane as combustor exit and slightly larger in diameter. This allows the conical water sheet to contact the hot exit gas almost immediately, preventing the hot gas from approaching the wall. The original splatter ring was affixed to the combustor liner by eight brass \#2 socket head cap screws. Brass was selected to allow the direct bolting of the brass screws to the tapped copper liner. The second version of the splatter ring used high strength stainless steel socket head cap screws with heli-coil inserts in the copper liner. The third and final version of the splatter ring has an integral machined flange on the upstream side that is sandwiched between the copper liner and spray cooler. Splatter ring failures will be discussed later.

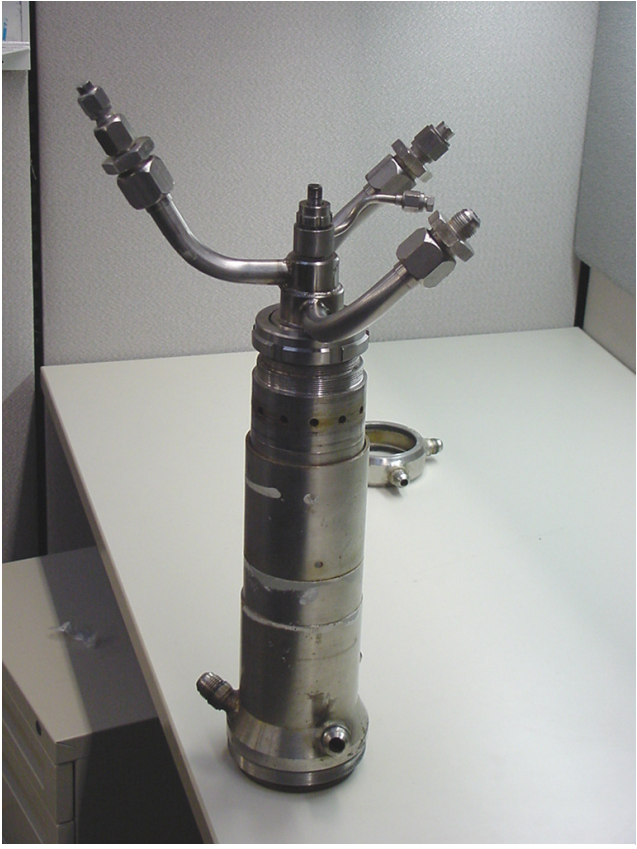

Figure 1. DTF/CSG Pressure Casing

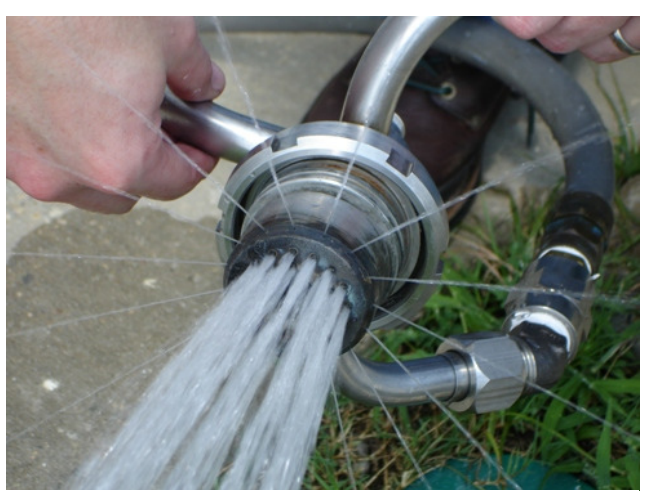

Figure 2. Injector Fuel Side Water Flow 


\section{B. Spray Cooler}

The spray cooler is used to inject the required water flow rate into hot combustion gases to create the desired steam temperature. The injected water must also force sufficient mixing to establish a uniform temperature distribution a reasonable distance downstream, namely upstream of the first change in flow direction. At E3, the first change in flow direction occurs at an L/d of approximately 50.

The spray cooler is constructed primarily of pipe stock. It is a jacketed pipe with the annulus between the outer and inner pipe creating the water injection plenum. Fabricated closure rings are welded to both the inner and outer pipe at either end of the plenum to seal the plenum. The upstream closure ring has blind tapped holes to allow the spray cooler to be bolted to the combustor. The combustor/spray cooler interface is sealed by a pair of o-rings on either side of the splatter ring flange. A flange is installed on the downstream end to interface with the steam transfer line. The inner pipe contains five rows of water injection holes. The first row of water injection holes are aligned normal to the pipe axis and are designed to impinge on the external contour of the splatter ring as discussed above. All subsequent rows of injection holes are aligned toward the downstream end of the spray cooler. Thus all water entering the spray cooler has a strong downstream component. This allows the injection water to be started slightly prior to rocket combustion without injecting water into the combustor. The second row of holes is sized to penetrate the hot combustor gas stream to nearly the pipe centerline to breakup the gas jet. Hole diameters are sequentially smaller in the streamwise direction to "trim" the mixture. Injection rows are also clocked such that adjacent rows do not inject water at the same circumferential location. Figure 3 shows a cross section of the combustor/spray cooler assembly. Figure 4 shows the combustor and spray cooler hardware installed.

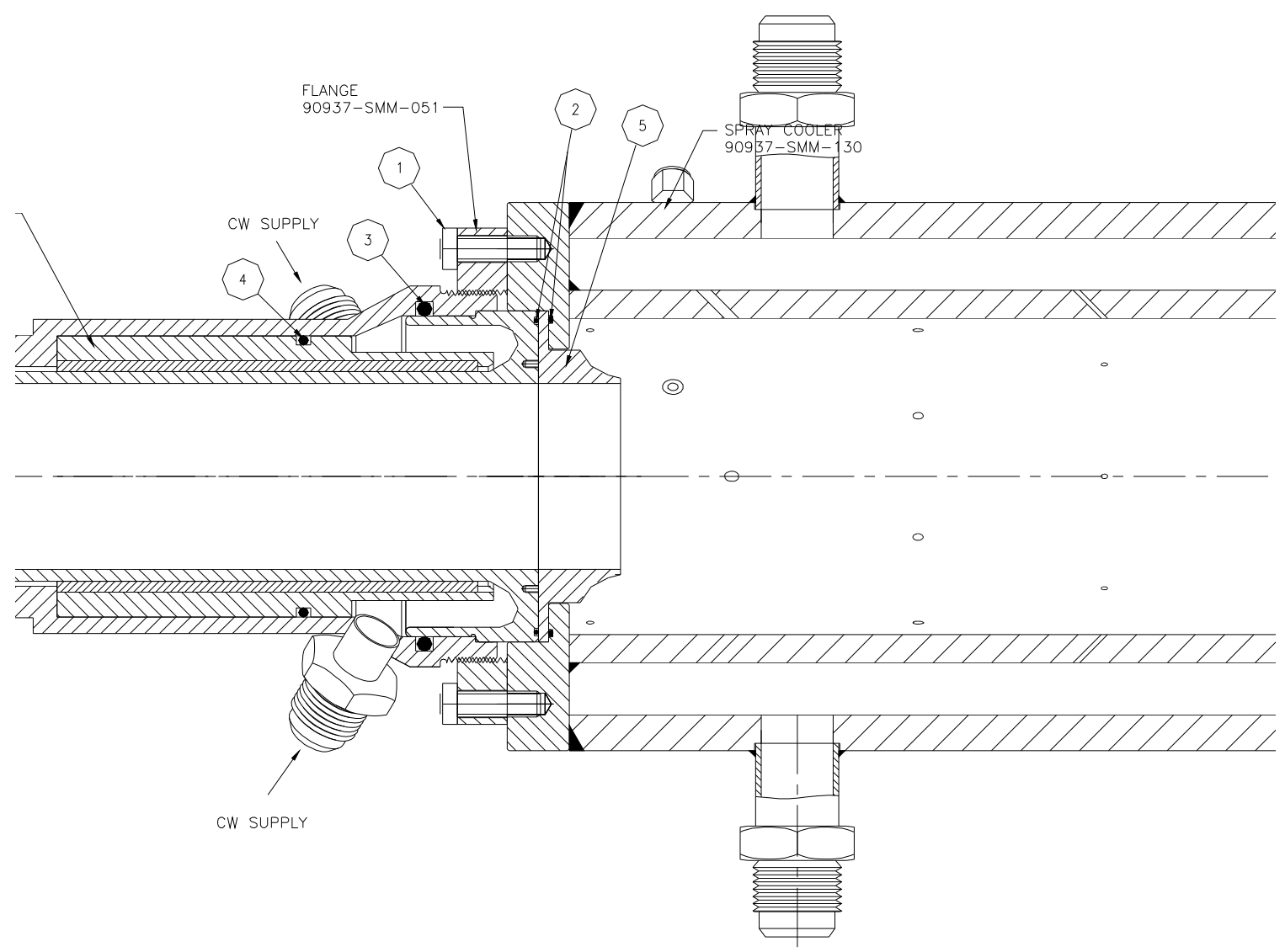

Figure 3. Combustor/Spray Cooler Interface Section 


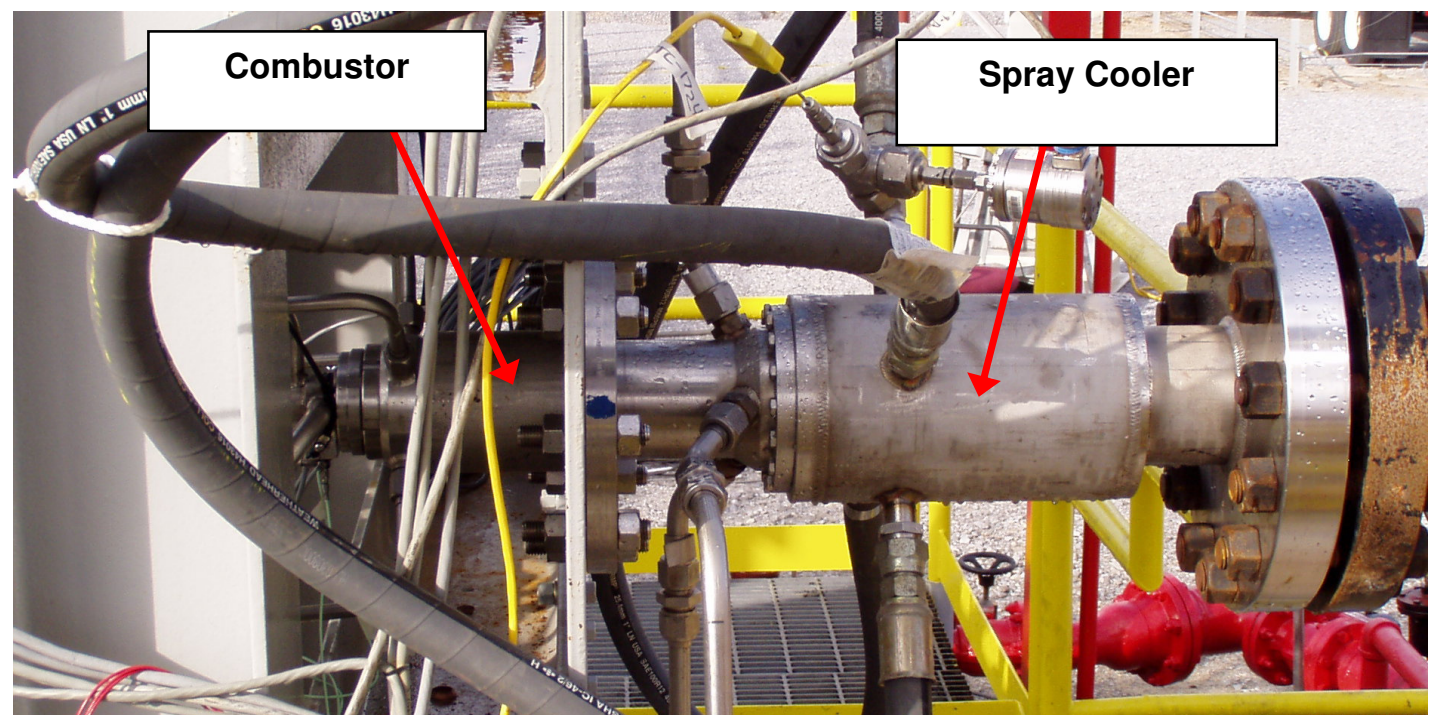

Figure 4. Steam Generator Combustor and Spray Cooler

\section{Activation}

Existing DTF hardware was assembled to run initial facility tests. The purpose of firing the old DTF hardware was mainly to shakedown the facility fuel, oxidizer, and liner cooling water systems. The DTF rocket had been run quite extensively in the past and substantial data was available for comparison. The DTF rocket was run at the same chamber pressure as planned for the steam chamber albeit at a somewhat lower flow rate limited by the DTF liner nozzle throat diameter. Figure 5 shows a firing of the DTF rocket motor.

\section{A. Steam Generation}

A steam generator activation spool section was then constructed to activate the no throat combustor liner and spray cooler. The activation spool was a straight section of pipe with a thermocouple "rake" to measure steam temperature distribution at an L/d of approximately 40 . An orifice was bored through a blind flange at the exit to simulate the required backpressure and a drain tube was installed to capture excess liquid water generated at startup and shutdown. Multiple activation tests were run at various water injection flow rates with the spool section installed to generate steam temperature versus water-to-propellant mass ratio plots for comparison to theory. The temperature range measured at the thermocouple "rake" was 10 to 15 deg F from the steam

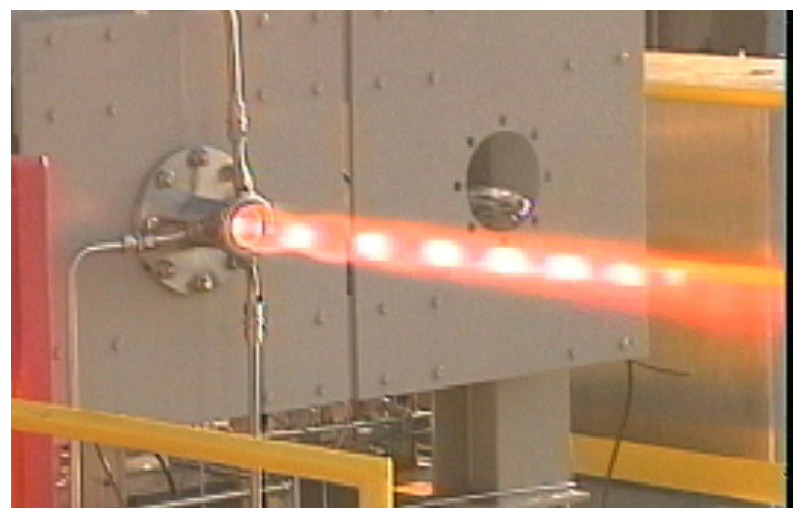

Figure 5. Initial Firing of DTF Rocket Motor pipe wall to centerline. Also, inlet and outlet temperature measurements on the liner cooling water allowed estimation of the total combustor enthalpy lost before combustion gases entered the spray cooler. It was found that approximately $5 \%$ of the total combustion enthalpy was rejected to the combustor liner cooling water. When this heat loss penalty was applied to the predicted total enthalpy, the

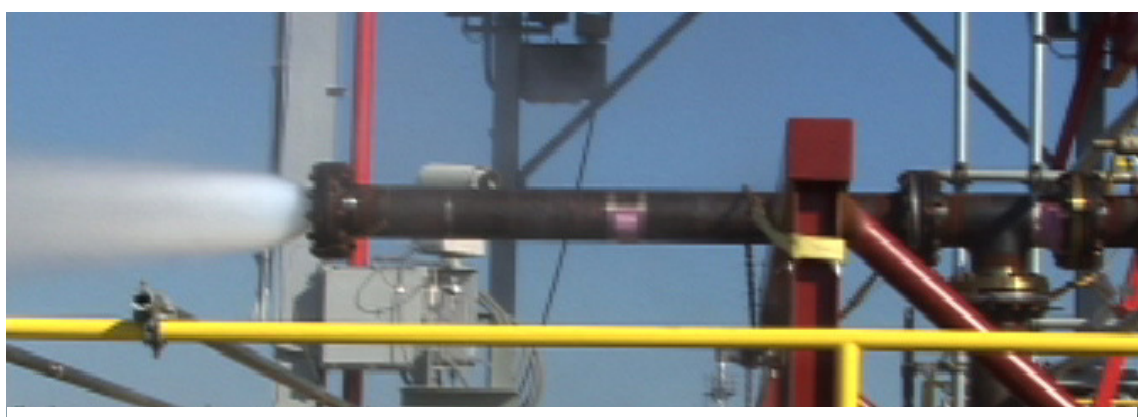

Figure 6. Steam Generator Firing with Activation Spool. 
calculated steam temperature was very accurate. Combustion chamber properties were predicted by using the Thermodynamic Equilibrium Program (TEP) by Software and Engineering Associates, which is essentially a commercial extension of Gordon and McBride's landmark NASA SP-273. The resultant chamber total enthalpy was then reduced based on the aforementioned cooling water temperature data. The reduced chamber enthalpy was then used to perform a simple first law energy balance to find the required water injection flows required to produce the desired steam temperature. A comparison of calculated water injection requirements and activation data is shown in Figure 7.

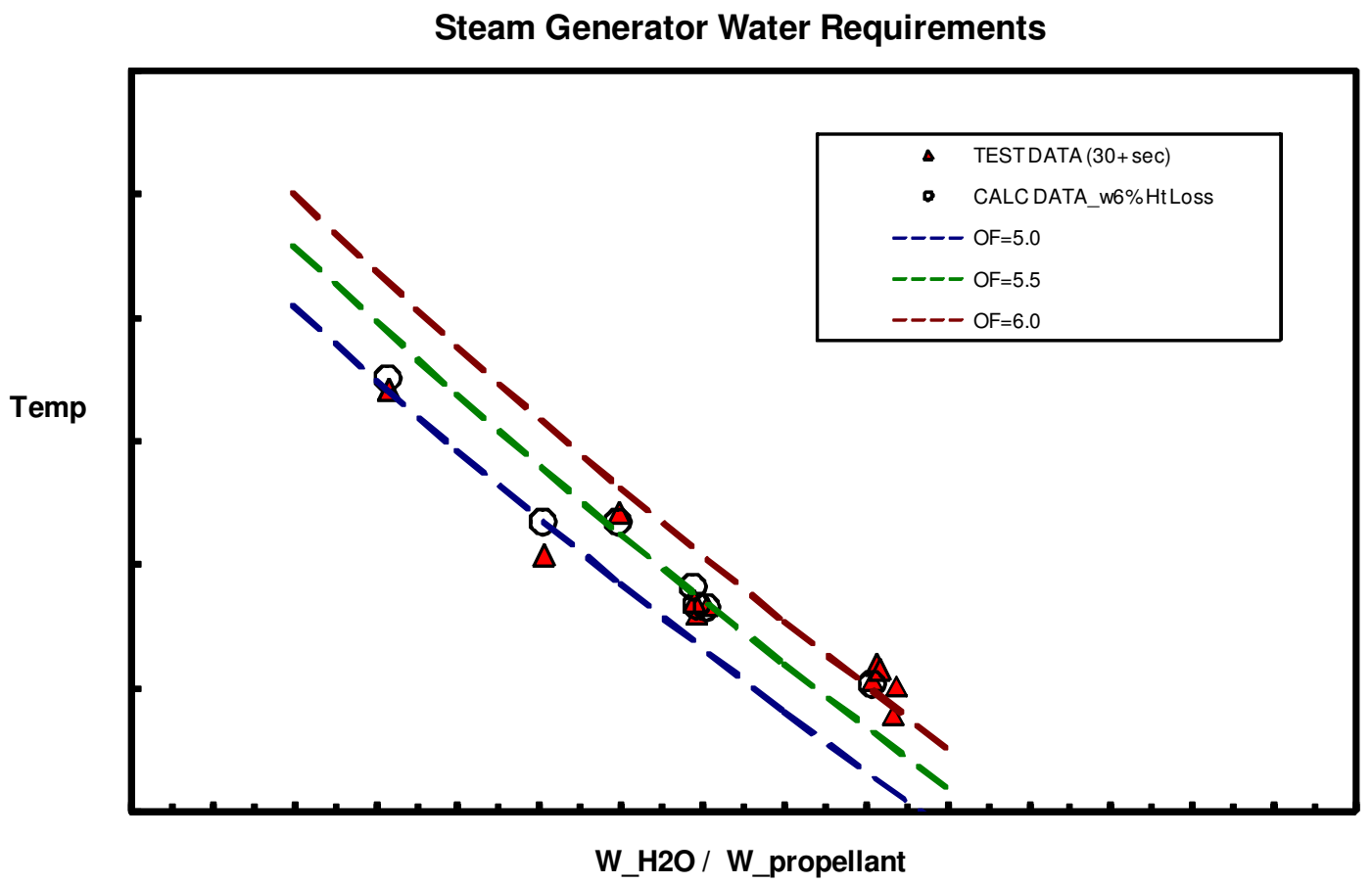

Figure 7. Comparison of Predicted Water Requirements and Activation Data

\section{B. Igniters}

An Estes model solid rocket motor was used as the igniter for all DTF and activation test firings. They were also used for early testing during the A3 subscale diffuser test program. The Estes motors are simple saltpeter (black powder) filled tubes. They were modified to allow remote starting from the E3 control room and installed in a stainless steel holder. While these igniters worked well, they required reloading between every test. Also, their burn time was so short that the main combustor fuel and oxidizer prevalves had to be opened prior to lighting the igniter. This was a safety concern once facility steam piping was installed as there was no way to prevent the admission

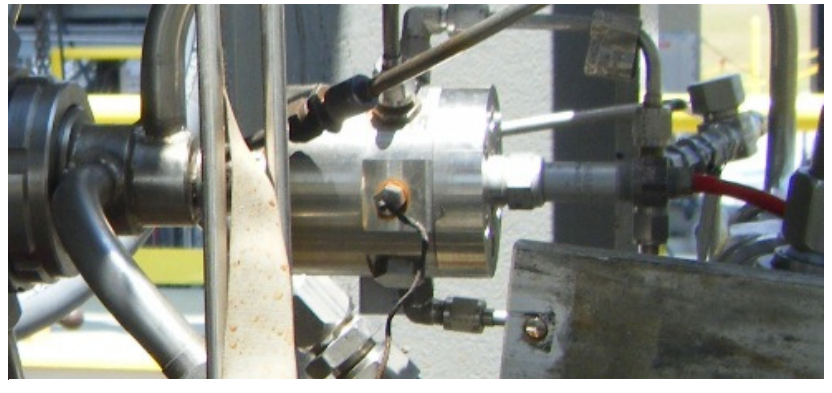

Figure 8. GOX/GH Spark Igniter of both fuel and oxidizer into the closed steam pipe in the event of a misfire. A GOX/GH spark igniter (Figure 8) was developed primarily for the J2-X scale simulator (JSS) rocket to allow for repeat firings. Once developed for the JSS application, the same design was adopted for use on the steam generator combustor. The use of the spark ignition system does not require maintenance between test firing and also can be started prior to the main combustor valves opening thus allowing a test termination without admitting propellants into the steam pipe. Details of the GOX/GH spark igniter development can be found in Reference 5. 


\section{Hardware Failures}

\section{Splatter Rings}

As stated in the design description above, the original splatter ring design was affixed to the aft end of the combustor using \#2-56 brass socket head cap screws to prevent galling of the drilled and tapped copper liner. This proved successful for approximately 1200 seconds of run time on the steam generator. The brass screws then experienced a tensile failure believed to be caused by thermal cycle fatigue and the splatter ring was released through the downstream piping where it came to rest at the steam pipe de-watering valve. This event allowed the hot combustor gas to freely expand to the spray cooler wall, gouging the cooler wall. Figure 9 shows a photo taken with a boroscope inside the spray cooler prior to splatter ring failure. Figure 10 shows the splatter ring and inside surface of the spray cooler after splatter ring failure.

The spray cooler was rebuilt with a new inside pipe and the \#2-56 brass screws were replaced with \#4-40 A286 high strength stainless steel socket head cap screws. Also, stainless steel heli-coil thread inserts were installed in the copper combustor liner to prevent thread

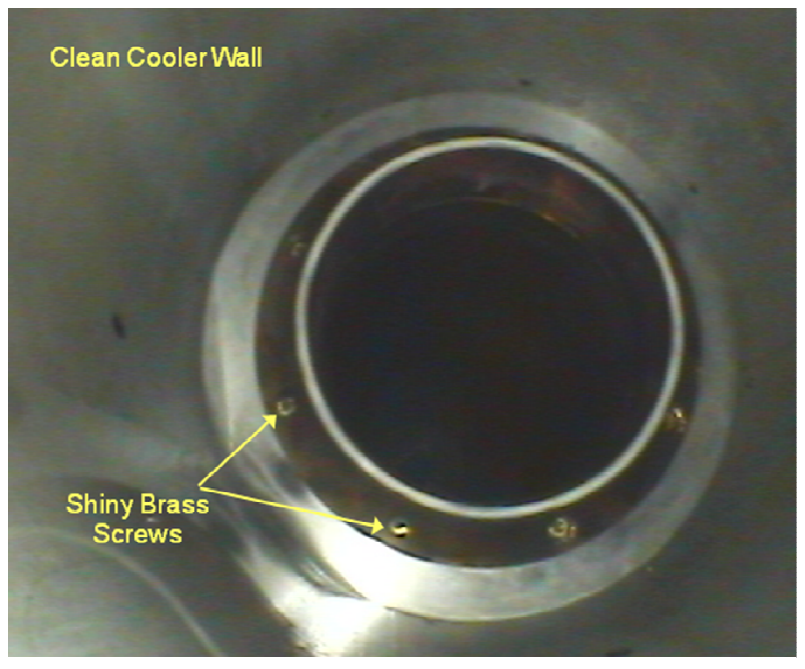

Figure 9. Boroscope Photo of Splatter Ring and Spray Cooler Wall Prior to Failure

damage. The splatter ring failed again. This time the stainless screws backed out due to high frequency vibrations driven by the combustion process.

Finally, the splatter ring was redesigned to include an integral 1/8" thick copper flange on the upstream end of the splatter ring. This flange is sandwiched between combustor liner and the spray cooler flange. Also, a gas side wall temperature measurement was added at the apparent peak temperature location (where maximum gouging occurred) so that a test could be terminated if the splatter ring became detached. Since the modifications were made, there have been no further splatter ring failures.

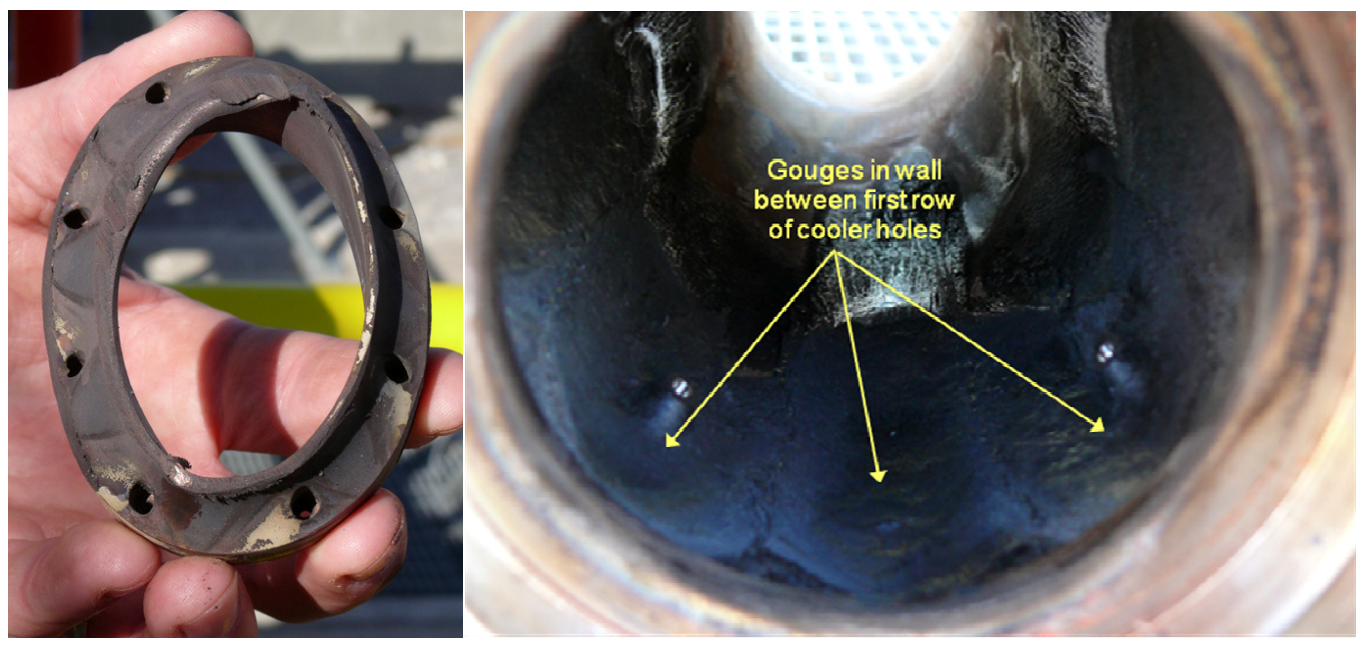

Figure 10. Photos of Splatter Ring and Spray Cooler After Ring Failure.

\section{Combustor Liner}

The initial no throat combustor liner failed after approximately 150 minutes of runtime. The liner wall weakened at the peak combustion region one to two diameters downstream of the injector. The combustor liner cooling water pressure is kept well above the combustor chamber; therefore the combustor line fails "safe". The only indication of liner failure is a reduction in total steam temperature because of the extra water injected into the combustion gas. A photo of the failed combustor liner in shown in Figure 11. 
Both cuprous and cupric oxides were discovered coating the water side wall. The predicted water side wall temperature of the liner is between 425 and 515 degrees $\mathrm{F}$ depending on the ambient water temperature. Copper oxides form readily at surface temperatures between 390 and 570 degrees $F$ when oxygen is present. The cooling water system uses site wide potable water; hence there is ample dissolved oxygen in the water supply. Cuprous oxide; (Copper(I) oxide), is generally red in color while Cupric oxide; (Copper (II) oxide), is black. The cupric oxide layer in particular is very detrimental to

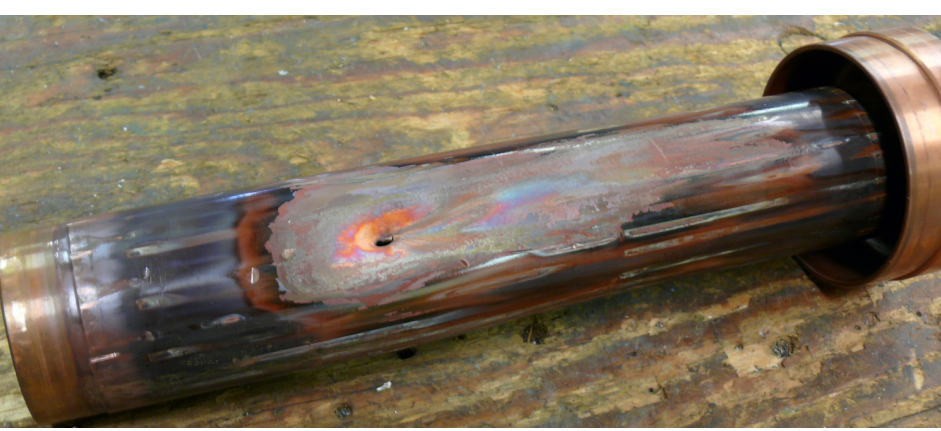

Figure 11. Photo of Failed Combustor Liner

the liner heat transfer properties. It has a thermal conductivity an order of magnitude lower than the pure copper. The oxide layer is also very smooth, reducing the water side convection heat transfer coefficient. Hence, the liner runs continually hotter test-to-test as the oxide layer builds, ultimately until liner failure. In lieu of building an oxygen free cooling water system, the liner is simply removed every 20 to 30 minutes of runtime and the oxide layer is removed on a lathe. Also, a spare liner is kept on hand eliminate downtime while the oxide layers are being removed. No further liner failures have occurred.

\section{Conclusions}

A LOX/GH steam generator has been successfully designed, activated, and has been in continual operation since October 2007. LOX/GH combustor and integral water injection spray cooler concepts have proven to be a very reliable steam generation system. Minimal maintenance is required to keep the system operational and there have been no hardware failures/issues other than those discussed above which were rectified during system activation.

\section{References}

${ }^{1}$ J. Ryan, C.A. Mulkey, N.G. Raines, G.P. Saunders, “An Overview of the A3 Subscale Diffuser Test Project”, AIAA-20084365, 2008

${ }^{2}$ G.P. Saunders, C.A. Mulkey, S.A. Taylor, "Design and Activation of a LOX/GH Chemical Steam Generator", AIAA-20095007,2009

${ }^{3}$ G.P. Saunders, “A3 Subscale Diffuser Test Article Design”, AIAA-2009-5010, 2009.

${ }^{4}$ G.P. Saunders, D.G. Varner, J.B. Grover, "Description and Operation of the A3 Subscale Facility", AIAA-2009-5097, 2009.

${ }^{5}$ G.P. Saunders, N.G. Raines, D.G. Varner, "Design, Activation, and Operation of the J2-X Subscale Simulator (JSS)", AIAA-2009-5098, 2009. 